\title{
Adapted tolerance to benzalkonium chloride in Escherichia coli K-12 studied by transcriptome and proteome analyses
}

\author{
Erlend Bore, ${ }^{1,2}$ Michel Hébraud, ${ }^{3,4}$ Ingrid Chafsey, ${ }^{3}$ Christophe Chambon, ${ }^{4}$ \\ Camilla Skjæret, ${ }^{1,2}$ Birgitte Moen, ${ }^{1,2}$ Trond Møretrø, ${ }^{1}$ Øyvind Langsrud, ${ }^{1}$ \\ Knut Rudi ${ }^{1}$ and Solveig Langsrud ${ }^{1}$ \\ ${ }^{1}$ Matforsk, Norwegian Food Research Institute, Osloveien 1, N-1430 Ås, Norway \\ ${ }^{2}$ The Norwegian University of Life Science (UMB), PO Box 5003, N-1432 Ås, Norway \\ UR454 Microbiologie-Equipe QuaSA, INRA site de Theix, 63122 Saint-Genès Champanelle, \\ France \\ ${ }^{4}$ Plate-forme Protéomique, INRA site de Theix, 63122 Saint-Genès Champanelle, France
}

Correspondence

Solveig Langsrud

solveig.langsrud@matforsk.no

Received 7 July 2006

Revised 9 October 2006

Accepted 21 December 2006

\section{INTRODUCTION}

Quaternary ammonium compounds (QACs) such as benzalkonium chloride (BC) and cetrimide are frequently used for disinfection and preservation. QACs are relatively stable, non-corrosive compounds with low toxicity and efficacy over a wide $\mathrm{pH}$ range. The destructive mechanism of QACs against bacteria is still not known in detail, but is thought to involve a general perturbation of the lipid bilayer in bacterial membranes. This leads to leakage of cytoplasmic material, damaging and ultimately killing the bacterial cell. For a review see Gilbert \& Moore (2005). The QACs have been actively deployed since the 1930s and one has not seen a

Abbreviations: 2-DE, two-dimensional gel electrophoresis; BC, benzalkonium chloride; Omp, outer-membrane protein; PPP, pentose phosphate pathway; QAC, quaternary ammonium compound; RTQ-PCR, realtime quantitative polymerase chain reaction.

The array data discussed in this publication have been deposited in NCBl's Gene Expression Omnibus (GEO, http://www.ncbi.nlm.nih.gov/ geo/) and are accessible through GEO Series accession number GSE6712.

A supplementary data file is available with the online version of this paper. resistance development similar to that seen for antibiotics in the same period. Still, there are numerous reports of QAC resistance (Heir et al., 1999; Langsrud et al., 2003; Wright \& Gilbert, 1987), most often associated with acquisition, or hyperexpression, of multi-drug efflux pumps (Li \& Nikaido, 2004; Tikhonova \& Zgurskaya, 2004), which has also been associated with changes in MIC of therapeutically important antibiotics serving as substrates to such pumps (Langsrud et al., 2004; Poole, 2004, 2005). Because of their relatively impermeable outer membrane, Gram-negative bacteria are intrinsically more resistant to QACs than Gram-positives (McDonnell \& Russell, 1999), but both Gram-negative and Gram-positive BC-resistant bacteria have been isolated from the food industry (Aase et al., 2000; Heir et al., 1995; Langsrud et al., 2003; Soumet et al., 2005).

Several studies have linked intrinsic/natural resistance of Gram-negative bacteria to tenside-based disinfectants, such as QACs, to the low permeability of the outer membrane, or broad-spectrum efflux systems (Denyer \& Maillard, 2002; Nikaido, 2001). Acquisition of resistance in Escherichia coli has been related mainly to changes in the composition of lipopolysaccharide (LPS) and fatty acids in the membrane (Ishikawa et al., 2002; Sakagami et al., 1989). In contrast to 
antibiotics, which have very specific targets within the bacterial cell, biocides affect multiple cellular components. We have earlier demonstrated that adaptation of E. coli to $\mathrm{BC}$ is followed by enhanced efflux activity and may result in cross-resistance to several antibiotics (Langsrud et al., 2004). In this study we describe changes in expression level at the transcriptomic and proteomic level for E. coli K-12 cells gradually adapted to a higher tolerance level to $\mathrm{BC}$. The results reveal that $\mathrm{BC}$ treatment may result in superoxide stress in Gram-negative bacteria.

\section{METHODS}

E. coli cell culture. The E. coli $\mathrm{K}-12$ strain selected for this work is a laboratory strain that was purchased from the American Type Culture Collection (ATCC 47076). The $4.6 \mathrm{Mbp}$ genome of E. coli $\mathrm{K}-12$ is the most thoroughly characterized amongst micro-organisms and contains 4290 predicted ORFs (Blattner et al., 1997). Cultures were stored in $16 \%(\mathrm{v} / \mathrm{v})$ glycerol at $-80{ }^{\circ} \mathrm{C}$. Unless otherwise stated the strain was cultivated at $37^{\circ} \mathrm{C}$ with shaking (200 r.p.m.).

Adaptation to benzalkonium chloride. E. coli K-12 was inoculated (two drops) into $5 \mathrm{ml}$ TSB with $\mathrm{BC}$ in a range of concentrations in $2 \mu \mathrm{g} \mathrm{ml}^{-1}$ steps. The cultures were incubated overnight $(20-24 \mathrm{~h})$ and inspected visually for growth. The tube with highest $\mathrm{BC}$ concentration with visible growth was reinoculated (two drops) into tubes with fresh TSB, with a range of $\mathrm{BC}$ concentrations in steps of $2 \mu \mathrm{g} \mathrm{ml}^{-1}$. The cultures were incubated overnight and inspected visually for growth. This procedure was continued for a total of 30-40 days until five reinoculations did not result in growth at higher concentrations of $\mathrm{BC}$. The adaptation process was performed three times, leading to the three biological repeats of adapted strains (A1, A2 and A3). Adapted strains and samples from several steps of the adaptation process were grown overnight in TSB without BC and kept frozen in $16 \%$ glycerol until use. PFGE was run to confirm the identity of the final adapted strain, using a Chef Electrophoresis Cell and Pulswave 760 (Bio-Rad), and essentially following the protocol of Bohm \& Karch (1992). All adapted strains were tested for stability of the tolerance level after freezing by four reinoculations and growth overnight in TSB without BC.

Harvesting of cells for RNA, DNA and protein analysis. Frozen cultures (control, A1, A2 and A3) were inoculated into $5 \mathrm{ml}$ TSB and incubated overnight. One millilitre of culture was inoculated in $99 \mathrm{ml}$ TSB in a $500 \mathrm{ml}$ baffled shake flask and incubated at $37^{\circ} \mathrm{C}$ with shaking. Adapted cultures were in addition grown in TSB with $50 \mu \mathrm{g} \mathrm{BC} \mathrm{ml}{ }^{-1}$. Bacterial cells were harvested at mid-exponential phase $\left(\sim 10^{8}\right.$ c.f.u. $\left.\mathrm{ml}^{-1}\right)$. For protein samples the culture was centrifuged at $5000 \mathrm{~g}$ for $10 \mathrm{~min}$ and washed three times in TE buffer $\mathrm{pH} 7.5$ (20 mM Tris, $5 \mathrm{mM}$ EDTA and $5 \mathrm{mM} \mathrm{MgCl}_{2}$ ), resuspended in $1 \mathrm{ml}$ TE buffer and frozen at $-80^{\circ} \mathrm{C}$. For DNA arrays, bacterial cells were harvested directly from the shake flask into RNAprotect (Qiagen) to secure stable RNA before cell lysis. One volume of culture $\left(1 \times 10^{8}\right.$ c.f.u. $\left.\mathrm{ml}^{-1}\right)$ was added to two volumes of RNAprotect, vortexed and incubated at room temperature for $5 \mathrm{~min}$. The sample was then centrifuged at $5000 \mathrm{~g}$ for $10 \mathrm{~min}$ and the supernatant removed.

Cultures for transcriptional and proteomic analysis were harvested three times on different days, resulting in three control samples and three samples for each adapted strain. Transcriptional analysis was performed for all samples. Protein analysis was performed for controls, A1 and A3 with 4-8 gels per sample.

Protein extraction - total soluble fraction. The protocols were mainly based on methods described by Molloy et al. (1999). The sample was centrifuged at $10^{\circ} \mathrm{C}$ and $7500 \mathrm{~g}$ for $10 \mathrm{~min}$. The pellet was resuspended in $1 \mathrm{ml}$ buffer 1 (40 mM Tris $\mathrm{pH} 9.5,5 \mathrm{mM}$ $\mathrm{MgCl}_{2}$ and $5 \mathrm{mM}$ EDTA). Then $10 \mu \mathrm{l}$ DNase I and $10 \mu \mathrm{l}$ RNase A were added and the tube was vortexed and kept at room temperature for $15 \mathrm{~min}$. The sample was then split into two fractions of $500 \mu \mathrm{l}$ each and sonicated using a Vibra-cell sonifier (Bioblock Scientific) with a Microsonde $l=138 \mathrm{~mm}$ and coupler $l=90 \mathrm{~mm}$. The sonication was run on ice as five cycles, alternating between $30 \mathrm{~s}$ at constant power level 5 and $2 \mathrm{~min}$ at power level 5 and $50 \%$ of the active cycle, separated by $1 \mathrm{~min}$ on ice between each single step. Five hundred microlitres of buffer 2 (40 mM Tris pH 9.5, $8 \mathrm{M}$ urea and $4 \%, w / v$, CHAPS) was added to each tube and the tubes vortexed. Just before use, $25 \mu \mathrm{l} 40 \%(\mathrm{v} / \mathrm{v})$ ampholyte 3-10 and $20 \mu \mathrm{l} 0.2 \mathrm{M}$ tributylphosphine were added to each tube. The samples were then centrifuged at $10^{\circ} \mathrm{C}, 13000 \mathrm{~g}$ for $15 \mathrm{~min}$. The supernatant was collected as the cellular protein fraction. The protein concentrations were determined for each fraction by the method of Bradford (1976) using the Bio-Rad protein assay kit with bovine serum albumin as the standard.

Two-dimensional electrophoresis (2-DE). 2-DE was performed essentially according to the method previously described by Folio et al. (2004). For isoelectric focusing, $18 \mathrm{~cm} \mathrm{pH} \mathrm{3-10} \mathrm{non-linear}$ (NL) immobilized $\mathrm{pH}$ gradient (IPG) strips (Bio-Rad) were rehydrated overnight with $400 \mu \mathrm{l}$ IEF buffer containing $60 \mu \mathrm{g}$ solubilized proteins (Folio et al., 2004). To improve focusing of protein spots in the gels, $50 \%$ trifluoroethanol was added to the rehydration buffer according to Deshusses et al. (2003).

Proteins were separated using a Multiphor II electrophoresis unit (Amersham Biosciences). After running the first dimension overnight, the IPG strips were equilibrated as previously described (Folio et al., 2004) and then placed on top of $12 \%$ acrylamide gels. The second dimension (SDS-PAGE) was carried out in a Multicell Protean II XL system (Bio-Rad) at $15 \mathrm{~mA}$ per gel and $40 \mathrm{~V}$ constant for $1 \mathrm{~h}$ and then at $150 \mathrm{~V}$ constant for about $15 \mathrm{~h}$.

Gels were silver stained according to the procedure of Rabilloud et al. (1992). For the identification of protein spots, semipreparative conditions were applied with $800 \mu \mathrm{g}$ of proteins and spots were detected using colloidal Coomassie blue stain according to the protocol of Neuhoff et al. (1988).

Gel analysis. Analysis of gel images was carried out using the softwares Z3 (Compugen) and Melanie 4.0 (GeneBio). 2-DE images of adapted and control E. coli were compared and qualitative and quantitative differences in spot patterns were analysed. Mean values using at least four gels from two independent protein extractions were taken into account for comparative analyses. The molecular masses and pI values were estimated via standard protein markers, and with theoretical IPG $\mathrm{pH}$ gradient and theoretical parameters of five identified spots.

Identification of proteins by MALDI-TOF-MS. Proteins were identified by MALDI-TOF-MS analysis (Proteomic Platform, INRA site de Theix, Clermont-Ferrand, France), using the peptide mass fingerprinting approach. One microlitre each of sample and saturated $\alpha$-cyano-4-hydroxycinnamic acid matrix $\left(10 \mathrm{mg} \mathrm{ml}^{-1}\right)$ in $50 \%$ acetonitrile and $0.1 \%$ TFA were mixed onto the target and allowed to dry. Positive-ion MALDI mass spectra were recorded in the reflectron mode of a MALDI-TOF-MS (Voyager DE-Pro; PerSeptive BioSystems), using Voyager software for data collection and analysis. The MS was calibrated with a standard peptide solution (Proteomix; LaserBio Labs). Trypsin autolysis peptides were used for internal calibration of samples. Monoisotopic peptide masses were assigned and used for NCBI database searches with the Mascot software (http://www.matrixscience.com). The following parameters were considered for the searches: a maximum fragment 
ion mass tolerance of \pm 25 p.p.m., a maximum of one missed enzymic cleavage, modification of cysteines by carbamidomethylation and possible oxidation of methionine.

Arrays. Total RNA was isolated using the RNeasy mini kit (Qiagen) according to the manufacturer's recommendations. The concentration of RNA was determined by measuring the absorbance at $260 \mathrm{~nm}$ and $280 \mathrm{~nm}$ in an Ultrospec 3000 spectrophotometer (Pharmacia Biotech). The ratio between the measured absorbance at the two wavelengths gives an estimate of RNA purity with respect to contamination (Qiagen Bench guide).

RNA degradation was checked with an Agilent 2100 Bioanalyser according to the userguide from Agilent Technologies. Before cDNA labelling, variations in RNA concentrations were adjusted to $1 \mu \mathrm{g} \mu \mathrm{l}^{-1}$ for all array hybridizations. Labelled cDNA was prepared according to the Panorama E. coli gene array protocol (Sigma Genosys), with some modifications. Superscript II Rnase $\mathrm{H}^{-}$reverse transcriptase (Invitrogen) and sheared salmon sperm DNA (Ambidon) replaced the equivalent components given in the Panorama protocol. The unincorporated nucleotides were removed with MicroSpinTM G-25 columns (Amersham Pharmacia Biotech), according to the protocol given. Purified labelled cDNAs were hybridized to the Panorama E. coli gene array, according to the protocol supplied. The membranes were wrapped in clear plastic film and exposed to a Storage Phosphor Screen (Amersham Biosciences) for $6-7$ days. $\left[\alpha^{33}\right.$ P]dCTP from Amersham Bioscience was used for all hybridizations but one, where the isotope was purchased from Montebello Diagnostics. The arrays were stripped between hybridizations according to the Panorama E. coli gene arrays technical protocol (Sigma Genosys).

The software Imagene (BioDiscovery) was used for quantification of data and the software Genespring (Silicon Genetics) for normalization.

Real-time quantitative PCR (RTQ-PCR). The quality of the Taqman data was secured through the use of two references, housekeeping genes gapA and $a c c D$. The Taqman probes and primers (Table 1) were found using the software SDS 2.2 and purchased from Applied Biosystems. The protocol used was essentially after Rudi et al. (2003). PCR samples and controls were prepared in triplicate. The reaction tubes were 96-Well Optical Reaction Plate and tube caps were Optical Adhesive Covers. Applied Biosystems supplied all consumables. Reactions were performed in the $7900 \mathrm{HT}$ Sequence Detection System from Applied Biosystems.

Antibiotic resistance. All strains were screened for antibiotic resistance using panels for monitoring of resistance in Gram-negative bacteria, VetMIC GN-mo (version 3) purchased from the National Veterinary Institute in Sweden. VetMIC is a microdilution method made and carried out in accordance with the recommendations and quality control methods recommended by NCCLS (2002), using known reference strains. The method is used in the Swedish (http:// www.sva.se), SVARM, Norwegian (http://www.zoonose.no),
NORM-VET and Finnish (http://www.eela.fi), FINRES, monitoring programmes (Petersen et al., 2003).

Overnight cultures in $\operatorname{TSB}\left(37^{\circ} \mathrm{C}, 200\right.$ r.p.m. $)$ were diluted to $10^{4}-$ $10^{5}$ c.f.u. $\mathrm{ml}^{-1}$ and $50 \mu \mathrm{l}$ was added to each of the 96 wells of the panel containing an antibiotic gradient for 13 different antibiotics. The panels were incubated for 2 days at $37^{\circ} \mathrm{C}$ and inspected for visible growth indicated by a pellet at the bottom of the wells after 1 and 2 days. The screening was repeated twice.

Statistics. The data were log-transformed and evaluated statistically according to the approach of Langsrud $(2002,2005)$ for analysing designed experiments with multiple responses. The analysis was based on an unbalanced analysis of variance model with the following model terms (degrees of freedom in parentheses): Strain (3), BC conc. (1), Biological repeats (2), Strain $\times B C$ conc. (2), Biological repeats $\times$ Strain (6). The presence of the Biological repeats $\times$ Strain interaction complicated the analysis. To ensure that our conclusions were general, we treated Biological repeats as a random factor. This means that the data were analysed according to a mixed-model approach where Strain was tested against Biological repeats $\times$ Strain as its error term. Since the current software for Langsrud's approach (available at http://www.matforsk.no/ola/program.htm) does not handle such models, a specialized routine was programmed in Matlab. To separate the adapted effect from the general Strain difference, the main effect of Strain was decomposed into two parts: Adapted (one degree of freedom) and the remaining part with two degrees of freedom.

With several multiple responses, ordinary significance testing leads to a lot of false significant results. Therefore, the $P$-values for each gene were adjusted by rotation testing according to a false discovery rate criterion (Moen et al., 2005).

In the analysis of a total of 4033 genes, observed difference needed to be relatively large to be judged as significant. Therefore, in addition to this analysis of (nearly) all genes, we ran an extra analysis with a smaller group of 25 pre-selected genes (acrABEF, cysDK, emrABDKY, fliY, marABR, mltAB, ompFR, soxS, tolC, yciQ, yhfZ, yhiUV). These 25 genes had been chosen from the literature for their relevance to resistance and stress prior to the analyses. In this case it was easier to detect significant results, since these genes did not need to compete with all the other 4008 (randomly varying) genes.

\section{RESULTS}

\section{Adaptation of $E$. coli K-12 to growth in BC}

The initial MIC of BC for E. coli ATCC 47076 was $13 \mu \mathrm{g} \mathrm{ml}^{-1}$; this level was increased to $80-90 \mu \mathrm{g} \mathrm{ml}^{-1}$ in three independently adapted strains. The level of BC

Table 1. Primers and probes used for RTQ-PCR

\begin{tabular}{|c|c|c|c|c|c|c|c|}
\hline Gene & $T_{\mathrm{m}}\left({ }^{\circ} \mathrm{C}\right)$ & Forward primer & $T_{\mathrm{m}}\left({ }^{\circ} \mathrm{C}\right)$ & Taqman MGB probe & $T_{\mathrm{m}}\left({ }^{\circ} \mathrm{C}\right)$ & Reverse primer & $T_{\mathrm{m}}\left({ }^{\circ} \mathrm{C}\right)$ \\
\hline$a c r B$ & 59 & GCGCTTTCTCGCAAATCAA & 69 & TGCGATGGTTTTCG & 59 & CGATTGCGGGCAGGT TAA & 59 \\
\hline marA & 59 & GGATCGAGGACAACCTGGAA & 68 & CGCCACTGTCACTGG & 59 & CCCGAACGCTCTGACACTTT & 57 \\
\hline$n f n B$ & 59 & AAAAACCGCGATGGACGAT & 69 & TCTGGCTGAAGCTGGT & 60 & TCGGCATCTTCCTGGTCAAC & 60 \\
\hline $\operatorname{soxS}$ & 58 & CATCAGACGCTTGGCGATT & 70 & CATTCGCCAACGCC & 58 & AACGGCGGCCAGTAACAG & 61 \\
\hline
\end{tabular}


tolerance was still above $80 \mu \mathrm{g} \mathrm{ml}^{-1}$ after freezing and after four passages in TSB containing no BC. PFGE confirmed that no contamination had occurred during the adaptation process by showing the same PFGE pattern for the adapted and the control strains.

\section{Transcriptional and proteomic analysis}

Initial experiments showed that it was difficult to extract sufficient protein from adapted cells pregrown in BC, and only results from adapted cells grown in TSB without BC were analysed further. More than 50 protein spots showed differences in expression between control and adapted strains, but for many of these spots there was high variation in expression between adapted strains, or it was not possible to identify the protein by MALDI-TOF-MS. Only identified proteins showing similar change of expression for all adapted strains and biological repeats analysed are discussed in the following.

Based on these criteria, the analyses of the protein data revealed 13 identified proteins (Table 2). For some proteins, such as RpsF and NfnB (Fig. 1; Table 2), several spots were identified and analysed.
The analysis of the array data revealed eight genes that showed significantly changed expression $(P<0.05)$ based on statistical analysis of a total of 4033 genes. In the statistical analysis based on 25 pre-selected genes, another five genes showed significant changes $(P<0.05)$. Results from the two analyses were then compared and the gene $a c r B$ was found to show significantly changed expression $(P<0.05)$ in both analyses. In addition mar $A$ showed a significance of $P<0.12$ in the 25 genes analysis and was included in the RTQ-PCR analysis (Table 3 ). The PCR confirmed the array data and confirmed that marA was upregulated in all adapted strains, although at only a small level in one of them. The effect of $\mathrm{BC}$ in the medium ( $B C$ conc.) varied between adapted strains and no genes showed significance $(P<0.05)$ for this. The statistical model term Strain $\times B C$ conc. showed significance $(P<0.05)$ for 105 genes (results not shown). These 105 genes are listed in supplementary material available with the online version of this paper (and also at http://www.matforsk.no/lab/ebo/1). Significance for this interaction indicates that there is some difference in genetic expression between $50 \mu \mathrm{g} \mathrm{ml}^{-1}$ and no BC in the medium, but this effect varied between adapted strains (A1, A2, A3) and no significant main effect for $B C$ conc. was shown. These genes are therefore not further discussed in the following.

Table 2. Genes and proteins differentially expressed in adapted vs control strain

Variations corresponding to arrays and protein gels given in italic and bold respectively. All strains for protein analysis and DNA array analysis were grown without $\mathrm{BC}$ in the medium. In addition the statistical analysis of the array data includes data from the adapted strains grown with $50 \mu \mathrm{g} \mathrm{BC} \mathrm{ml}{ }^{-1}$ in the medium.

\begin{tabular}{|c|c|c|c|}
\hline Function & Gene or protein & Ratio A/C & Comment \\
\hline \multirow[t]{2}{*}{ Global regulators } & $\operatorname{soxS}$ & 13.4 & Oxidative stress protection \\
\hline & marA & 4.7 & Multiple antibiotic resistance \\
\hline \multirow[t]{7}{*}{ Stress related } & $n f n B^{*}$ & 7.1 & Oxygen-insensitive $\mathrm{NAD}(\mathrm{P}) \mathrm{H}$ nitroreductase \\
\hline & $\mathrm{NfnB}^{*}$ & $2-5$ & \\
\hline & Ssb & $0.16-0.54$ & Single-stranded DNA-binding protein \\
\hline & $y b j C^{*}$ & 9.2 & Conserved hypothetical protein, part of sox regulon \\
\hline & $\mathrm{MnSOD}^{*}$ & & Manganese superoxide dismutase \\
\hline & $f l d A^{*}$ & 3.4 & Flavodoxin \\
\hline & MdaB & 4.3 & $\mathrm{NADPH}$ quinone reductase \\
\hline \multirow[t]{4}{*}{ Metabolic enzymes } & FumC $^{*}$ & 2.0 & Fumarate hydratase \\
\hline & $z w f^{*}$ & 3.6 & PPP enzyme glucose-6-phosphate dehydrogenase \\
\hline & $g c d$ & 4.2 & PPP enzyme membrane-bound glucose dehydrogenase \\
\hline & gapA & 2.1 & Glyceraldehyde-3-phosphate dehydrogenase A, glycolysis \\
\hline \multirow[t]{2}{*}{ RpoS regulon } & WrbA & 0.31 & Trp repressor-binding protein \\
\hline & Dps & 0.12 & DNA-binding protein \\
\hline \multirow[t]{3}{*}{ Transporter genes } & yeeF & 0.44 & Amino acid APC transporter \\
\hline & $y h i V$ & 2.2 & Multidrug transporter \\
\hline & $\operatorname{acr} A^{\star}, \operatorname{acr} B^{\star}$ & $2.5,3.7$ & Multidrug exporter \\
\hline Ribosomal subunits & RpsF & See Fig. 1 & $30 \mathrm{~S}$ ribosomal subunit S6 \\
\hline \multirow[t]{4}{*}{ Outer-membrane proteins } & tolC & 2.2 & Associated with efflux pumps \\
\hline & OmpA, OmpF, OmpT & $0.17-0.29$ & Porins \\
\hline & OmpC & 3.9 & Porin \\
\hline & FecA & 0.27 & Outer-membrane ferric citrate receptor \\
\hline
\end{tabular}

${ }^{*}$ sox/mar regulated. 



Fig. 1. Typical 2-DE-gel images of E. coli ATCC 47076 control strain (A) and E. coli ATCC 47076 adapted to BC (B). The first-dimension separation of proteins according to $\mathrm{pl}$ is shown along the non-linear $\mathrm{pH}$ gradient ( $\mathrm{pl} 3-10$ ) on the horizontal axis. The second-dimension separation of proteins according to molecular mass is seen along the vertical axis ( $k D a)$. The enlarged detail (C) is a composite picture in colours showing the expression of ribosomal subunit RpsF in control (green) and $\mathrm{BC}$-adapted (pink) bacterial cells. The colours are complementary, meaning that equal expression levels in both strains shows as black spots. For each spot a dominant green colour indicates a downregulated and a dominant pink colour an upregulated level of expression in the adapted strain.

Table 3. RTQ-PCR results showing differential expression in adapted vs control strain

Results are given as $n$ in $2^{n}$, representing fold change in relation to the housekeeping $\operatorname{gap} A$ and $\operatorname{accD}$ genes.

\begin{tabular}{|lcrrrrrrr|}
\hline Housekeeping gene & Adapted line & soxS & marA & nfnB & acrB & zwf & mdaB & ompF \\
\hline \multirow{2}{*}{ gapA } & A1 & 4.50 & 5.90 & 3.07 & 2.40 & 2.40 & 2.55 & -2.47 \\
& A2 & 2.79 & -0.77 & 0.01 & -0.63 & 0.71 & -1.25 & -6.28 \\
\multirow{3}{*}{ accD } & A3 & 6.44 & 1.15 & 1.95 & 2.08 & 3.03 & 1.18 & 0.33 \\
& A1 & 3.86 & 5.05 & 2.43 & 1.75 & 1.76 & 1,91 & -3.11 \\
& A2 & 6.19 & 1.82 & 3.41 & 2.76 & 4.11 & 2.15 \\
& A3 & 6.24 & 0.36 & 1.75 & 1.88 & 2.83 & 0.98 & 0.13 \\
\hline
\end{tabular}




\section{Global regulators soxS and marA and genes they regulate}

The array data showed that expression of the global regulator soxS increased significantly in adapted cells (Table 2). A large upregulation of the global regulator marA was also seen in two of the three adapted lines (A1 and A2) but only a small increase in the third adapted line (A3) placed mar $A$ outside the $5 \%$ significance level $(P=0.118)$. A significant effect of adapted line variation was also calculated for marA $(P=0.018)$. RTQ-PCR confirmed that marA was upregulated in all adapted lines, but that the upregulation in one adapted line was small. In this strain (A3) the expression level of marA increased early in the adaptation process, but then came close to the expression level of the control strain towards the end of the adaptation process (Fig. 2). Our results showed a significant increase in expression of $a c r A B$ and tolC. Testing for adapted line variation showed significance for $\operatorname{acr} B(P=0.051)$, but RTQ-PCR confirmed the upregulation of acrB in all adapted lines (Table 3). RTQPCR also showed (Fig. 2) that the upregulation of $a c r B$ took place in the early part of the adaptation, without any further increase in the level of expression throughout the adaptation process.

SoxS is the activator of the soxSR regulon, which includes at least 15 genes, including several whose products play a direct role in responding to oxidative stress. Our results show elevated expression for soxS and several sox regulon-related genes. RTQ-PCR was used to study how the expression level of some of these genes developed (Table 3, Fig. 2), through the gradual increase in $\mathrm{BC}$ tolerance level during the adaptation process. Both macroarrays and RTQ-PCR showed a striking upregulation for soxS. The curve throughout the adaptation process (Fig. 2) clearly shows high upregulated levels of soxS already in the early adaptation steps, but also that the level continued to increase throughout the adaptation process.

Although at a much lower level of overexpression than soxS, the sox regulon genes $z w f$ and $n f n B$ were both significantly upregulated in the adapted strains. The gene $z w f$ encoding glucose-6-phosphate dehydrogenase, which is the first enzyme leading into the pentose phosphate pathway (PPP), is known to be trancriptionally activated by SoxS when exposed to oxidative stress (Greenberg et al., 1990) and by antibiotics through marA (Cohen et al., 1993). Another glucose dehydrogenase gene, $g c d$, was also shown to be upregulated in adapted strains at a similar ratio to $z w f$ (Table 2), but the relation of this gene to the soxRS regulon has never been described.

$\mathrm{NfnB}$ is a minor E. coli oxygen-insensitive nitroreductase that uses both NADPH and NADH as cofactors. Transcription of $n f n B$ is known to be highly increased by induced or constitutive chromosomal expression of marA, but is unaltered by constitutive expression of chromosomal soxS (Barbosa \& Levy, 2002). In the protein gels, $\mathrm{NfnB}$ was identified in three spots with the same molecular mass, but different pI values (Fig. 1).

\section{Other transporter genes}

Besides the sox- and mar-regulated $a c r A B$ multidrug exporter, the gene $y h i V$ also shows a significant increase in its level of expression. This gene is a component of the YhiUV multidrug transporter tolC, which is also upregulated in the macroarrays, and is required for proper YhiUV

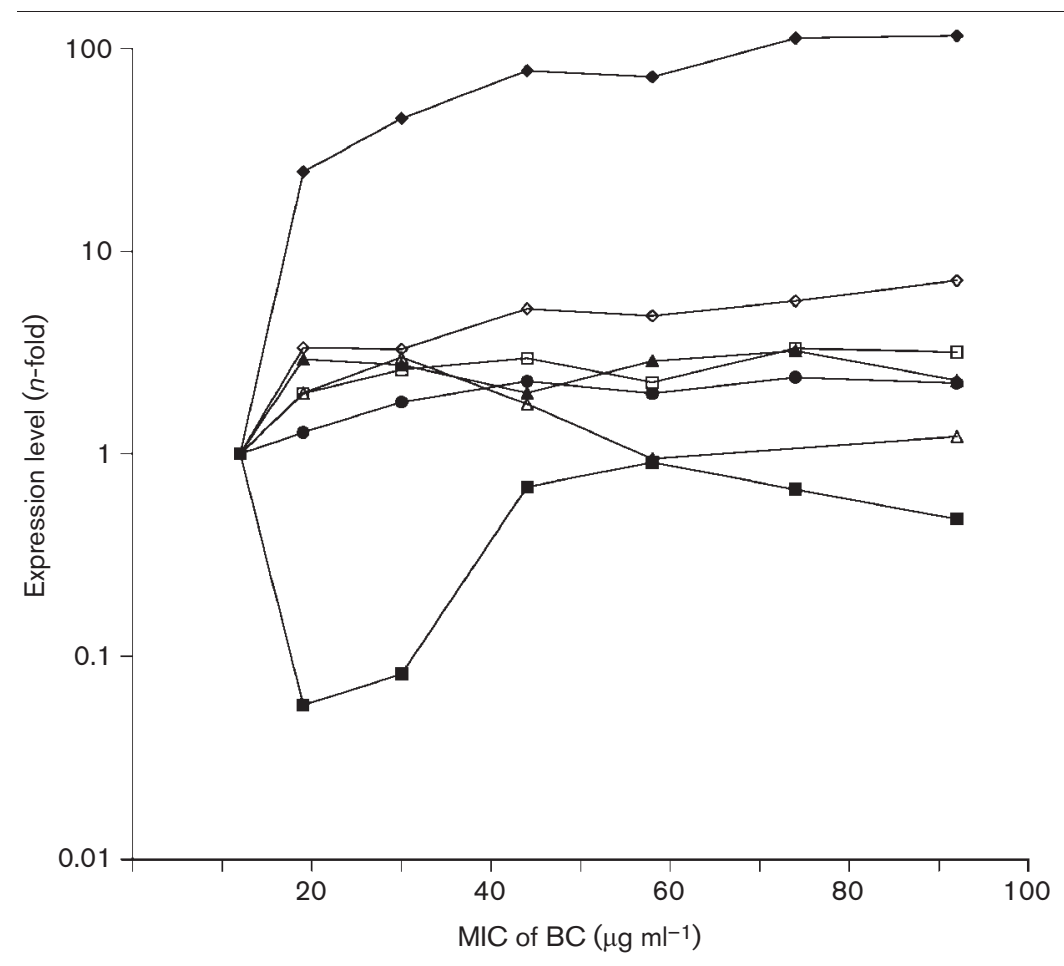

Fig. 2. RTQ-PCR data showing the fold change in expression level of the genes soxS $(\Delta), \operatorname{mar} A(\triangle), \operatorname{nfn} B(\square), \operatorname{acr} B(\boldsymbol{\Delta})$, $z w f(\diamond), m d a B(\bullet)$ and ompF $(\boldsymbol{\square})$ through the stepwise adaptation of $E$. coli ATCC 47076 to $\mathrm{BC}$ from an initial MIC of $13 \mu \mathrm{g} \mathrm{ml}^{-1}$ to a final MIC of $92 \mu \mathrm{g} \mathrm{ml}^{-1}$ in the adapted strain A3. An expression level of 1 in the graph indicates an equal level of expression in control and adapted strain. An expression level $>1$ indicates increased expression while an expression level $<1.00$ indicates decreased expression level of a gene through adaptation. The data in the figure are normalized to the expression of the housekeeping gene $a c c D$. 
transporter function (Zgurskaya \& Nikaido, 2000). The gene yee $F$ encoding an amino acid APC transporter showed a reduced level of expression (Table 2).

\section{Outer-membrane proteins (Omps)}

The 2-DE shows a change in expression for several Omps, including TolC already mentioned (Table 2). OmpA, OmpF and OmpT were found to be downregulated while OmpC was upregulated in adapted strains. OmpF, OmpC and OmpT are general bacterial porins and it is well known that when osmotic pressure increases, OmpF decreases and OmpC increases and vice versa. Ishikawa et al. (2002) also found a higher relative content of OmpC than $\mathrm{OmpF}$ in accordance with higher BC tolerance in E. coli. Our Taqman analysis for $o m p F$ showed an initial response opposed to that of soxS, with a steep decrease in expression for initial adaptation steps. Then, the level of expression increased again and normalized half way through the adaptation process (Fig. 2) and stayed close to normal level for the last adaptation steps $\left(\sim 50-100 \mu \mathrm{g} \mathrm{ml}^{-1}\right)$. The Taqman results for the end-point in the adaptation of the different adapted lines (Table 3) indicate that this normalization of ompF expression level occurred in only one of the three adapted lines. The two other adapted strains remained downregulated to a significant level at the end of the adaptation process (Table 3 ).

\section{Modifications of ribosomal subunits}

A cluster of spots (Fig. 1) in the lower range of both pI and molecular mass was identified by MALDI-TOF as RpsF protein (30S ribosomal subunit S6). Two of these spots disappeared in patterns of control cells while RpsF spots with slightly higher molecular mass and lower pI appeared in patterns of adapted cells. These modifications indicate that RpsF seems to be post-translationally modified in the adapted strain. RpsF has two glutamic acid residues (Glu) in its C-terminus and it is known that additional Glu residues can be added post-translationally to the C-terminus by the enzyme RimK (Kang et al., 1989; Wilcox et al., 2001). Mutations in ribosomal subunits have been observed to confirm resistance to antibiotics (Allen \& Noller, 1989; Bilgin et al., 1990; Chittum \& Champney, 1994; Funatsu et al., 1972), and thus it can be assumed that the new RpsF spots observed in adapted cells correspond to posttranslational modifications of the protein involved in cell tolerance to BC.

\section{Other stress-related genes}

The MdaB protein (NADPH quinone reductase) was significantly upregulated in the 2-DE gels (Table 2). Little has been published on this protein, but Wang \& Maier (2004) concluded that it plays an important role in oxidative stress resistance in Helicobacter pylori. Moreover, Barbosa \& Levy (2000) showed that the gene was upregulated along with constitutive expression of MarA. The $m d a B$ gene seems to increase less during the first adaptation step than the sox regulon genes (Fig. 2), but it still showed a significant increase in the level of expression when compared to the control and it continued to increase throughout the adaptation process.

Ssb, the single-stranded DNA-binding protein, binds to single-stranded DNA at the lagging strand of the replication fork in E. coli cells (Eisenman \& Craig, 2004; Witte et al., 2003). The 2-DE patterns show Ssb to be underexpressed in adapted strains. Others have recently shown Ssb to be upregulated in $\mathrm{pH}$-tolerant oral streptococci (Len et al., 2004) and Ssb has also been shown to be induced upon UV treatment, but downregulated by mitomycin C-induced damage (Courcelle et al., 2001; Khil \& Camerini-Otero, 2002).

The major global regulator gene $d p s$ showed a significant change in expression in the protein gels (Fig. 1). Dps (DNAbinding protein) is primarily produced in stationary phase and has been shown to be regulated by OxyR, $\sigma^{38}$ and $\sigma^{70}$ (Altuvia et al., 1994; Azam et al., 1999; Lomovskaya et al., 1994). Nishino \& Yamaguchi (2004) showed that another global regulator, $\mathrm{H}-\mathrm{NS}$, contributes to multidrug resistance, including to $\mathrm{BC}$, by regulating the expression of multidrug exporter genes. They showed that a double deletion mutant hns acr $A B$ had increased resistance to $\mathrm{BC}$ while no change was observed for an hns mutant and concluded that H-NS represses the expression of acrEF and $y h i U V$ ( $m d t E F)$. However, our protein data for H-NS varied significantly between adapted lines, making it difficult to draw any final conclusions on the importance of this regulator.

\section{Antibiotic tolerance of adapted strains}

Table 4 shows antibiotic tolerance concentrations for the control and adapted strains. All adapted strains showed an increase in antibiotic tolerance for chloramphenicol, florfenicol, ciprofloxacin, nalidixic acid, ampicillin and cefotaxime. Increased susceptibility was shown for gentamicin, streptomycin and kanamycin.

\section{DISCUSSION}

Acquisition of surfactant resistance in E. coli has been related mainly to changes in the composition of LPS and fatty acids in the membrane (Ishikawa et al., 2002; Sakagami et al., 1989). We have earlier demonstrated that adaptation of $E$. coli to BC is followed by enhanced efflux activity and may result in cross-resistance to several antibiotics (Langsrud et al., 2004). The results of the current work showed that the BC-adapted E. coli strains have acquired defence mechanisms normally related to oxidative protection, and increased tolerance to antibiotics was confirmed.

sox $S$ was by far the most upregulated gene in our arrays. It is known that soxS and marA contribute to intrinsic resistance to several antibiotics and chemicals in E. coli (for a review, see Randall \& Woodward, 2002), and that overproduction of SoxS leads to a higher superoxide resistance than 
Table 4. Panel for monitoring of antibiotic resistance in Gram-negative bacteria

The control strain and four adapted lines were tested. The numbers given are the MIC of each antibiotic $\left(\mu \mathrm{g} \mathrm{ml}^{-1}\right)$ : Am, ampicillin; $\mathrm{Ci}$, ciprofloxacin; Nal, nalidixic acid; $\mathrm{Gm}$, gentamicin; Ce, ceftiofur; Sm, streptomycin; Tc, tetracycline; Ff, florfenicol; Km, kanamycin; Cm, chloramphenicol; Ctx, cefotaxime. Results that differed between repeated experiments are given as intervals (e.g. 2-4). All other results did not differ when repeated.

\begin{tabular}{|lcccccccccccl|}
\hline Strain & Am & Ci & Nal & Gm & Ce & Sm & Tc & Ff & Km & Cm & Ctx \\
\hline Control & 4 & 0.06 & 8 & $2-4$ & 0.5 & $16-32$ & 2 & 8 & 16 & 8 & 0.06 \\
A1 & 8 & 0.25 & 64 & 1 & 2 & $4-8$ & 4 & 64 & $2-4$ & 128 & 0.5 \\
A2 & $4-8$ & 0.25 & 32 & 2 & 1 & $8-16$ & 4 & $16-32$ & 8 & $8-16$ & 0.12 \\
A3 & 8 & 0.25 & 32 & 2 & 2 & 16 & $4-8$ & 32 & 8 & $16-32$ & 0.25 \\
\hline
\end{tabular}

overproduction of MarA (Martin et al., 2000). Our results showed a striking upregulation of several genes known to belong to the soxRS regulon, as would be expected for cells exposed to an oxidative stress component. Basically, E. coli cells possess two genetic defence systems for response to oxidative stress: one specific defence against peroxides, mediated by the transcriptional activator OxyR (Zheng et al., 2001), and one against superoxide (Pomposiello et al., 2001) that is controlled by the two-stage soxRS system (for a review, see Cabiscol et al., 2000). Induction of defence mechanisms against oxidative stress has been linked to other stress responses such as acid stress responses. Maurer et al. (2005) showed that low $\mathrm{pH}$ accelerates acid consumption and proton export in E. coli, while co-inducing oxidative stress and heat shock regulons. Others have shown that overexpression of soxS in E. coli produces resistance to the antimicrobial agent triclosan (McMurry et al., 1998). When it comes to QACs such as $\mathrm{BC}$, a recent study on $\mathrm{BC}$ effects on Chang conjunctival cells showed that QACs induced superoxide synthesis at low concentrations (Debbasch et al., 2001). To our knowledge there has not been published any clear link between acquired resistance to QACs, such as $\mathrm{BC}$, and oxidative stress response in bacteria.

Cationic surfactants, including QACs, are known to disrupt cell membranes and interrupt protein functions, releasing $\mathrm{K}^{+}$and other cell constituents and inducing cell autolysis. Majtan et al. (1995) reported that the QAC (1-methyldodecyl)trimethylammonium bromide inhibits respiratory activity in Pseudomonas aeruginosa. Under aerobic growth, disruption of the cell membrane by $\mathrm{BC}$ activity could disrupt the electron-transport chain and thereby increase the level of highly reactive oxygen radicals in the cell. This indirect oxidative stress would cause a depletion of $\mathrm{NADPH}$ followed by activation of the soxRS regulon as observed in our results. 2-DE showed a significant increase in the expression level of manganese superoxide dismutase (MnSOD) (Table 2, Fig. 1). MnSOD is the primary antioxidant enzyme that protects cells from oxidative stress by catalysing dismutation of superoxide $\left(\mathrm{O}_{2}^{-{ }^{-}}\right)$to hydrogen peroxide and oxygen. It is uniformly distributed throughout the cytoplasm in prokaryotic cells, binds to DNA and protects it from oxidative damage (Steinman \& Weinstein, 1993; Steinman et al., 1994). The MnSOD gene sodA is part of the soxRS regulon and is transcriptionally regulated by at least six control systems (Compan \& Touati, 1993; Nunoshiba et al., 1992; Wu \& Weiss, 1992). The increase in MnSOD levels in the adapted cells helps to minimize depletion of NADPH, as does also induction of the PPP through Zwf, by increasing production of NADPH. Besides $z w f$, we also observed an increase in the expression of $g c d$, encoding another dehydrogenase. Gcd is known to be involved in the formation of membrane potentials, feeding electrons obtained from the oxidation of glucose to ubiquinone and ubiquinol oxidase (van Schie et al., 1985; Yamada et al., 1993b). Gcd is negatively regulated by cAMP and positively by oxygen (Yamada et al., 1993a).

FldA (flavodoxin I), one of the two known flavodoxins in $E$. coli and also known to belong to the soxRS oxidative stress regulon, was significantly upregulated in the adapted strains (Table 2). The same was the case for fumC (fumarase C) (Paterson et al., 2002). Upregulation of fumC, as observed in our data (Table 2), is also a part of the cellular defence against oxidative stress through the replacement of redoxsensitive isozymes by redox-resistant isozymes (fumarase C). FumC activity has also been shown to be upregulated as a response to high oxygen levels (Liochev \& Fridovich, 1992; Tseng et al., 2001).

Our results showed significant upregulation of the $n f n B$ gene (synonym $n f_{s} B$ ), encoding an oxygen-insensitive nitroreductase, while we saw no evidence for increased expression of $n f s A$. On the other hand, we found the $y b j C$ gene (conserved hypothetical protein) to be upregulated in adapted strains. This gene is located directly upstream of $n f_{S} A$ in the sox regulon, cotranscribed with $n f_{S} A$, which suggests that these two genes form an operon (Paterson et al., 2002). NfsA is the major nitroreductase and uses $\mathrm{NADPH}$ as the electron donor. In a macroarray study, Barbosa \& Levy (2000) showed $n f n B$, as well as $n f s A$, to be MarA responsive and they found a significant change for $n f n B$ and $y b j C$, but not for $n f_{s} A$ under constitutive expression of MarA. Their data suggested that MarA is preferred over SoxS in upregulating $n f n B$ and further work by the same authors supported this conclusion (Barbosa \& Levy, 2002). Our results corroborate those of Barbosa \& Levy (2000) for many of the observed changes in our adapted strains. The expression level of $n f n B$ is lower for the adapted line (Table 3, A3) that showed the lowest level of marA expression. Due to the increase in expression we observed for marA and several genes known to be affected by constitutive expression of MarA, it is likely that this protein plays a regulatory role in the increased resistance to $\mathrm{BC}$ in the adapted cells. However, the variation between adapted lines for this gene, as opposed to the highly statistically significant upregulation of soxS, points to soxS as the most important regulator in the general adapted resistance to $\mathrm{BC}$. 
Both marA and soxS encode positive regulators of $a c r A B$ and upregulate $a c r A B$, which encodes a stress-induced multidrug efflux pump formed by the AcrAB-TolC complex across the membranes (Ma et al., 1995). This AcrAB-TolC efflux pump has been linked to intrinsic resistance to BC (Moken et al., 1997). Our results showed a significant increase in expression of $a c r A B$ and tolC.

There was no support in our results for any variation of gene or protein expression in the OxyR system, except a reduced expression of Dps in adapted cells as observed in 2-DE gels. $d p s$ is also part of the RpoS growth phase regulon and most work published on this protein refers to upregulation of its expression as a defence mechanism against oxidative damage by peroxides during the exponential growth phase (Almiron et al., 1992; Choi et al., 2000; Martinez \& Kolter, 1997; Martinez-Martinez et al., 2000). Our data also showed a downregulated level of another member of the RpoS regulon, the WrbA protein. It therefore stands to reason that the RpoS regulon could be repressed in the adapted strains, although further work would have to be done to confirm this. Results of bactericidal tests (not shown) showed a much higher survival ratio for E. coli control cells in the exponential phase than in the stationary phase. In the stationary phase, Dps is known to be active in DNA protection by presence in high molecule numbers and against multiple stress factors such as UV, copper, thermal, acid and base shock (Almiron et al., 1992; Nair \& Finkel, 2004; Wolf et al., 1999). Kirkpatrick et al. (2001) showed repressed levels of Dps and other RpoS regulon proteins for E. coli exposed to formate stress, as opposed to acetate stress, which led to increased expression of the same proteins. They hypothesized that the level of acetylCoA could be involved in regulation of this response. The activation of the soxRS regulon leads to induction of the PPP through glucose-6-phosphate dehydrogenase (Zwf) with corresponding reversion of the glycolysis (glyconeogenesis) to meet the urgent demand for reducing power (NADPH). The need to metabolize pyruvate through other pathways then arises, resulting in a reduction of actyl-CoA levels, which could explain the reduced level of the Dps protein in our adapted strains.

Changes in the cell membrane with alteration of the LPS composition have been described for QACs and this might lead to a tighter membrane structure, making it harder to extract proteins. On the other hand, recent work by Braoudaki \& Hilton (2005) concluded that a sublethal concentration of $\mathrm{BC}$ did not lead to any significant changes in outer membrane or LPS, but that preadapted strains proved less hydrophobic than resistant strains. We observed that the pellets of cells grown in the presence of $\mathrm{BC}$ were dark brownish in colour and stuck strongly to the inside of the test tubes. The lower $\mathrm{OD}_{600}$ we observed for adapted cells at mid-exponential phase $\left(10^{8}\right.$ c.f.u. $\left.\mathrm{ml}^{-1}\right)$ could also indicate a change in cell size.

Observed changes in Omps and in particular the upregulation of the small porin $\mathrm{OmpC}$ and the downregulation of the larger porin $\mathrm{OmpF}$ is well described in the literature as a mechanism to reduce access through the cell membrane (Ishikawa et al., 2002). The Taqman results for $o m p F$, which showed a normalization of the ompF level after an initial decrease in expression level for one of the adapted lines, could indicate that the $o m p F$ response is not critical for the BC-resistant strain. One explanation could be that BC cannot pass through the OmpF porin, but that the switch from the large porin $\mathrm{OmpF}$ to the smaller porin $\mathrm{OmpC}$ is a general stress response, not actually protecting the cell from BC. Another explanation could be that as other adapted resistance mechanisms become stronger, the OmpF downregulation in early adapted cells is no longer needed to cope with the $\mathrm{BC}$ threat. This presupposes that $\mathrm{BC}$ can enter the cell through the OmpF porin, which is yet to be verified. Loss of OmpF has been shown to be one of the resistance mechanisms elaborated by $E$. coli against $\beta$-lactam antibiotics (Martinez-Martinez et al., 2000) and fluoroquinolones (Tavio et al., 1999). It is known that $\beta$-lactams such as ampicillin, which are molecules close to $\mathrm{BC}$ in size, can bind to and pass through the OmpF porin (Nestorovich et al., 2002) and interestingly the antibiotic panel testing (Table 2) showed an increase in tolerance to ampicillin.

The protein data indicate post-translational modifications of the S6 ribosomal subunit encoded by the $r p s F$ gene. Several of the antibiotics showing increased tolerance for adapted strains in our screening tests (gentamicin, tetracycline, chloramphenicol, streptomycin) have killing mechanisms linked to ribosomal activity. One might speculate whether ribosomal modification is a likely crossresistance mechanism between $\mathrm{BC}$ and certain antibiotics. Further work is needed to clarify this issue.

The variation in curve profiles for the adaptation process indicates that different genetic approaches could lead to the same resistance level and/or that some adaptation steps could be more difficult to acquire. This is further supported by the significant differences between adapted lines in the expression of genes such as marA and ompF.

The gapA gene is a common reference for Taqman results, but our results showed a variation in the level of expression of the GapA protein. Therefore, we decided to use another commonly used reference and housekeeping gene, $a c c D$, as a second reference for these experiments. The results showed that one of the adapted lines differed from the others when gapA was used as a reference. This confirmed that the expression of gapA was more strongly upregulated in some adapted lines than in others. For two out of three adapted lines, however, the gapA reference gave the same pattern of change in level of expression as $a c c D$. The change in gapA level in adapted strains could be explained by increased flux through the PPP, producing $\mathrm{NADPH}$ and returning glyceraldehyde 3-phosphate to glycolytic metabolism and then running either glyconeogenesis, or the second part of glycolysis to pyruvate.

The average signal in the DNA arrays was relatively low. Therefore there are probably smaller $(<2$-fold $)$ but 
significant changes in the expression of several genes that are not seen in these results. The data presented represent the largest changes in expression level between adapted strains and control strain and are clearly significant for repeated experiments. There is overlap between protein data and DNA array data, and the PCR data confirm the other data.

In summary, E. coli K-12 adapted to higher tolerance to BC acquired several general resistance mechanisms including responses normally related to the multiple antibiotic resistance (Mar) regulon and protection against oxidative stress. Adapted strains showed increased tolerance to several antibiotics and the results revealed that $\mathrm{BC}$ treatment might result in superoxide stress in E. coli.

\section{ACKNOWLEDGEMENTS}

This work was supported by the Fund for Research Levy on Agricultural Products (Norway), grant 142656/140 from the Research Council of Norway (NFR) and a 2003-1 Fellowship from the Federation of European Microbiological Societies (FEMS).

The authors acknowledge the assistance of Signe M. Drømtorp in performing RTQ-PCR, Dr Kristine Naterstad for sharing her experience in PFGE, Dr Lars Axelsson and Dr Akild Holck for fruitful discussions on the subject of stress responses and Dr Jean Labadie for initiating the co-operation on this particular project between Matforsk-Norway and INRA-France.

\section{REFERENCES}

Aase, B., Sundheim, G., Langsrud, S. \& Rorvik, L. M. (2000). Occurrence of and a possible mechanism for resistance to a quaternary ammonium compound in Listeria monocytogenes. Int J Food Microbiol 62, 57-63.

Allen, P. N. \& Noller, H. F. (1989). Mutations in ribosomal protein-S4 and protein-S12 influence the higher-order structure of $16-\mathrm{S}$ ribosomal-RNA. J Mol Biol 208, 457-468.

Almiron, M., Link, A. J., Furlong, D. \& Kolter, R. (1992). A novel DNA-binding protein with regulatory and protective roles in starved Escherichia coli. Genes Dev 6, 2646-2654.

Altuvia, S., Almiron, M., Huisman, G., Kolter, R. \& Storz, G. (1994). The Dps promoter is activated by Oxyr during growth and by Ihf and a Sigma(S) in stationary-phase. Mol Microbiol 13, 265-272.

Azam, T. A., Iwata, A., Nishimura, A., Ueda, S. \& Ishihama, A. (1999). Growth phase-dependent variation in protein composition of the Escherichia coli nucleoid. J Bacteriol 181, 6361-6370.

Barbosa, T. M. \& Levy, S. B. (2000). Differential expression of over 60 chromosomal genes in Escherichia coli by constitutive expression of MarA. J Bacteriol 182, 3467-3474.

Barbosa, T. M. \& Levy, S. B. (2002). Activation of the Escherichia coli $n f n B$ gene by MarA through a highly divergent marbox in a class II promoter. Mol Microbiol 45, 191-202.

Bilgin, N., Richter, A. A., Ehrenberg, M., Dahlberg, A. E. \& Kurland, C. G. (1990). Ribosomal-RNA and protein mutants resistant to spectinomycin. EMBO J 9, 735-739.

Blattner, F. R., Plunkett, G., Bloch, C. A., Perna, N. T., Burland, V., Riley, M., Collado-Vides, J., Glasner, J. D., Rode, C. K. \& other authors (1997). The complete genome sequence of Escherichia coli K-12. Science 277, 1453-1474.
Bohm, H. \& Karch, H. (1992). DNA fingerprinting of Escherichia coli O157-H7 strains by pulsed-field gel-electrophoresis. J Clin Microbiol 30, 2169-2172.

Bradford, M. M. (1976). Rapid and sensitive method for quantitation of microgram quantities of protein utilizing principle of protein-dye binding. Anal Biochem 72, 248-254.

Braoudaki, M. \& Hilton, A. C. (2005). Mechanisms of resistance in Salmonella enterica adapted to erythromycin, benzalkonium chloride and triclosan. Int J Antimicrob Agents 25, 31-37.

Cabiscol, E., Tamarit, J. \& Ros, J. (2000). Oxidative stress in bacteria and protein damage by reactive oxygen species. Int Microbiol 3, 3-8.

Chittum, H. S. \& Champney, W. S. (1994). Ribosomal-protein gene sequence changes in erythromycin-resistant mutants of Escherichia coli. J Bacteriol 176, 6192-6198.

Choi, S. H., Baumler, D. J. \& Kaspar, C. W. (2000). Contribution of $d p s$ to acid stress tolerance and oxidative stress tolerance in Escherichia coli O157:H7. Appl Environ Microbiol 66, 3911-3916.

Cohen, S. P., Hachler, H. \& Levy, S. B. (1993). Genetic and functional analysis of the multiple antibiotic-resistance (Mar) locus in Escherichia coli. J Bacteriol 175, 1484-1492.

Compan, I. \& Touati, D. (1993). Interaction of six global transcription regulators in expression of manganese superoxide dismutase in Escherichia coli K-12. J Bacteriol 175, 1687-1696.

Courcelle, J., Khodursky, A., Peter, B., Brown, P. O. \& Hanawalt, P. C. (2001). Comparative gene expression profiles following UV exposure in wild-type and SOS-deficient Escherichia coli. Genetics 158, 41-64.

Debbasch, C., Brignole, F., Pisella, P. J., Warnet, J. M., Rat, P. \& Baudouin, C. (2001). Quaternary ammoniums and other preservatives' contribution in oxidative stress and apoptosis on Chang conjunctival cells. Invest Ophthalmol Vis Sci 42, 642-652.

Denyer, S. P. \& Maillard, J. Y. (2002). Cellular impermeability and uptake of biocides and antibiotics in Gram-negative bacteria. J Appl Microbiol 92 (Suppl.), 35S-45S.

Deshusses, J. M. P., Burgess, J. A., Scherl, A., Wenger, Y., Walter, N., Converset, V., Paesano, S., Corthals, G. L., Hochstrasser, D. F. \& Sanchez, J. C. (2003). Exploitation of specific properties of trifluoroethanol for extraction and separation of membrane proteins. Proteomics 3, 1418-1424.

Eisenman, H. C. \& Craig, E. A. (2004). Activation of pleiotropic drug resistance by the J-protein and Hsp70-related proteins, Zuol and Ssz1. Mol Microbiol 53, 335-344.

Folio, P., Chavant, P., Chafsey, I., Belkorchia, A., Chambon, C. \& Hébraud, M. (2004). Two-dimensional electrophoresis database of Listeria monocytogenes EGDe proteome and proteomic analysis of mid-log and stationary growth phase cells. Proteomics 4, 3187-3201.

Funatsu, G., Wittmann, H. G. \& Schiltz, E. (1972). Ribosomalproteins. 27. Localization of amino-acid exchanges in protein S5 from two Escherichia coli mutants resistant to spectinomycin. Mol Gen Genet 114, 106-111.

Gilbert, P. \& Moore, L. E. (2005). Cationic antiseptics: diversity of action under a common epithet. J Appl Microbiol 99, 703-715.

Greenberg, J. T., Monach, P., Chou, J. H., Josephy, P. D. \& Demple, B. (1990). Positive control of a global antioxidant defense regulon activated by superoxide-generating agents in Escherichia coli. Proc Natl Acad Sci U S A 87, 6181-6185.

Heir, E., Sundheim, G. \& Holck, A. L. (1995). Resistance to quaternary ammonium compounds in Staphylococcus spp. isolated from the food industry and nucleotide sequence of the resistance plasmid pST827. J Appl Microbiol 79, 149-156.

Heir, E., Sundheim, G. \& Holck, A. L. (1999). The qacG gene on plasmid pST94 confers resistance to quaternary ammonium 
compounds in staphylococci isolated from the food industry. $J$ Appl Microbiol 86, 378-388.

Ishikawa, S., Matsumura, Y., Yoshizako, F. \& Tsuchido, T. (2002). Characterization of a cationic surfactant-resistant mutant isolated spontaneously from Escherichia coli. J Appl Microbiol 92, 261-268.

Kang, W. K., Icho, T., Isono, S., Kitakawa, M. \& Isono, K. (1989). Characterization of the gene rimk responsible for the addition of glutamic-acid residues to the C-terminus of ribosomal protein-S6 in Escherichia coli K12. Mol Gen Genet 217, 281-288.

Khil, P. P. \& Camerini-Otero, R. D. (2002). Over 1000 genes are involved in the DNA damage response of Escherichia coli. Mol Microbiol 44, 89-105.

Kirkpatrick, C., Maurer, L. M., Oyelakin, N. E., Yoncheva, Y. N., Maurer, R. \& Slonczewski, J. L. (2001). Acetate and formate stress: opposite responses in the proteome of Escherichia coli. J Bacteriol 183, 6466-6477.

Langsrud, Ø. (2002). 50-50 multivariate analysis of variance for collinear responses. J R Stat Soc Ser D 51, 305-317.

Langsrud, Ø. (2005). Rotation tests. Stat Comput 15, 53-60.

Langsrud, S., Sundheim, G. \& Borgmann-Strahsen, R. (2003). Intrinsic and acquired resistance to quaternary ammonium compounds in food-related Pseudomonas spp. J Appl Microbiol 95, 874-882.

Langsrud, S., Sundheim, G. \& Holck, A. L. (2004). Cross-resistance to antibiotics of Escherichia coli adapted to benzalkonium chloride or exposed to stress-inducers. J Appl Microbiol 96, 201-208.

Len, A. C. L., Harty, D. W. S. \& Jacques, N. A. (2004). Stressresponsive proteins are upregulated in Streptococcus mutans during acid tolerance. Microbiology 150, 1339-1351.

Li, X. Z. \& Nikaido, H. (2004). Efflux-mediated drug resistance in bacteria. Drugs 64, 159-204.

Liochev, S. I. \& Fridovich, I. (1992). Fumarase-C, the stable fumarase of Escherichia coli, is controlled by the SoxRS regulon. Proc Natl Acad Sci U S A 89, 5892-5896.

Lomovskaya, O. L., Kidwell, J. P. \& Matin, A. (1994). Characterization of the sigma(38)-dependent expression of a core Escherichia coli starvation gene, pexb. J Bacteriol 176, 3928-3935.

Ma, D., Cook, D. N., Alberti, M., Pon, N. G., Nikaido, H. \& Hearst, J. E. (1995). Genes acrA and $a c r B$ encode a stress-induced efflux system of Escherichia coli. Mol Microbiol 16, 45-55.

Majtan, V., Majtanova, L., Hostacka, A., Hybenova, D. \& Mlynarcik, D. (1995). Effect of quaternary ammonium salts and amine oxides on Pseudomonas aeruginosa. Microbios 84, 41-51.

Martin, R. G., Gillette, W. K. \& Rosner, J. L. (2000). Promoter discrimination by the related transcriptional activators MarA and SoxS: differential regulation by differential binding. Mol Microbiol 35, 623-634.

Martinez, A. \& Kolter, R. (1997). Protection of DNA during oxidative stress by the nonspecific DNA-binding protein Dps. J Bacteriol 179, 5188-5194.

Martinez-Martinez, L., Conejo, M. C., Pascual, A., Hernandez-Alles, S., Ballesta, S., De Arellano-Ramos, E. R., Benedi, V. J. \& Perea, E. J. (2000). Activities of imipenem and cephalosporins against clonally related strains of Escherichia coli hyperproducing chromosomal betalactamase and showing altered porin profiles. Antimicrob Agents Chemother 44, 2534-2536.

Maurer, L. M., Yohannes, E., Bondurant, S. S., Radmacher, M. \& Slonczewski, J. L. (2005). pH regulates genes for flagellar motility, catabolism, and oxidative stress in Escherichia coli K-12. J Bacteriol 187, 304-319.

McDonnell, G. \& Russell, A. D. (1999). Antiseptics and disinfectants: activity, action, and resistance. Clin Microbiol Rev 12, 147-179.
McMurry, L. M., Oethinger, M. \& Levy, S. B. (1998). Overexpression of marA, soxS, or acr $A B$ produces resistance to triclosan in laboratory and clinical strains of Escherichia coli. FEMS Microbiol Lett 166, 305-309.

Moen, B., Oust, A., Langsrud, O., Dorrell, N., Marsden, G. L., Hinds, J., Kohler, A., Wren, B. W. \& Rudi, K. (2005). Explorative multifactor approach for investigating global survival mechanisms of Campylobacter jejuni under environmental conditions. Appl Environ Microbiol 71, 2086-2094.

Moken, M. C., McMurry, L. M. \& Levy, S. B. (1997). Selection of multiple-antibiotic-resistant (Mar) mutants of Escherichia coli by using the disinfectant pine oil: roles of the mar and $a c r A B$ loci. Antimicrob Agents Chemother 41, 2770-2772.

Molloy, M. P., Herbert, B. R., Williams, K. L. \& Gooley, A. A. (1999). Extraction of Escherichia coli proteins with organic solvents prior to two-dimensional electrophoresis. Electrophoresis 20, 701-704.

Nair, S. \& Finkel, S. E. (2004). Dps protects cells against multiple stresses during stationary phase. J Bacteriol 186, 4192-4198.

NCCLS (2002). Methods for Dilution Antimicrobial Susceptibility Tests for Bacteria that Grow Aerobically. NCCLS approved standard M7-A5. Wayne, PA: National Committee for Clinical Laboratory Standards. Nestorovich, E. M., Danelon, C., Winterhalter, M. \& Bezrukov, S. M. (2002). Designed to penetrate: time-resolved interaction of single antibiotic molecules with bacterial pores. Proc Natl Acad Sci U S A 99, 9789-9794.

Neuhoff, V., Arold, N., Taube, D. \& Ehrhardt, W. (1988). Improved staining of proteins in polyacrylamide gels including isoelectric focusing gels with clear background at nanogram sensitivity using Coomassie Brilliant Blue G-250 and R-250. Electrophoresis 9, 255-262.

Nikaido, H. (2001). Preventing drug access to targets: cell surface permeability barriers and active efflux in bacteria. Semin Cell Dev Biol 12, 215-223.

Nishino, K. \& Yamaguchi, A. (2004). Role of histone-like protein HNS in multidrug resistance of Escherichia coli. J Bacteriol 186, 1423-1429.

Nunoshiba, T., Hidalgo, E., Amabile Cuevas, C. F. \& Demple, B. (1992). Two-stage control of an oxidative stress regulon: the Escherichia coli SoxR protein triggers redox-inducible expression of the soxS regulatory gene. J Bacteriol 174, 6054-6060.

Paterson, E. S., Boucher, S. E. \& Lambert, I. B. (2002). Regulation of the $n f_{S A}$ gene in Escherichia coli by SoxS. J Bacteriol 184, 51-58.

Petersen, A., Aarestrup, F. M., Hofshagen, M., Sipulä, H., Franklin, A. \& Gunnarsson, E. (2003). Harmonization of antimicrobial susceptibility testing among veterinary diagnostic laboratories in the five Nordic countries. Microbial Drug Resist 9, 381-388.

Pomposiello, P. J., Bennik, M. H. \& Demple, B. (2001). Genomewide transcriptional profiling of the Escherichia coli responses to superoxide stress and sodium salicylate. J Bacteriol 183, 3890-3902.

Poole, K. (2004). Efflux-mediated multiresistance in Gram-negative bacteria. Clin Microbiol Infect 10, 12-26.

Poole, K. (2005). Efflux-mediated antimicrobial resistance. J Antimicrob Chemother 56, 20-51.

Rabilloud, T., Brodard, V., Peltre, G., Righetti, P. G. \& Ettori, C. (1992). Modified silver staining for immobilized $\mathrm{pH}$ gradients. Electrophoresis 13, 264-266.

Randall, L. P. \& Woodward, M. J. (2002). The multiple antibiotic resistance (mar) locus and its significance. Res Vet Sci 72, 87-93.

Rudi, K., Nogva, H. K., Naterstad, K., Dromtorp, S. M., Bredholt, S. \& Holck, A. (2003). Subtyping Listeria monocytogenes through the combined analyses of genotype and expression of the hlyA virulence determinant. J Appl Microbiol 94, 720-732. 
Sakagami, Y., Yokoyama, H., Nishimura, H., Ose, Y. \& Tashima, T. (1989). Mechanism of resistance to benzalkonium chloride by Pseudomonas aeruginosa. Appl Environ Microbiol 55, 2036-2040.

Soumet, C., Ragimbeau, C. \& Maris, P. (2005). Screening of benzalkonium chloride resistance in Listeria monocytogenes strains isolated during cold smoked fish production. Lett Appl Microbiol 41, 291-296.

Steinman, H. M. \& Weinstein, L. (1993). Manganese superoxidedismutase of Escherichia coli binds DNA - Escherichia coli FeSod does not - implications for in-vivo function. Free Radic Biol Med 15, 476.

Steinman, H. M., Weinstein, L. \& Brenowitz, M. (1994). The manganese superoxide-dismutase of Escherichia coli $\mathrm{K}-12$ associates with DNA. J Biol Chem 269, 28629-28634.

Tavio, M. D., Vila, J., Ruiz, J., Martin-Sanchez, A. M. \& de Anta, M. T. J. (1999). Mechanisms involved in the development of resistance to fluoroquinolones in Escherichia coli isolates. J Antimicrob Chemother 44, 735-742.

Tikhonova, E. B. \& Zgurskaya, H. I. (2004). AcrA, AcrB, and TolC of Escherichia coli form a stable intermembrane multidrug efflux complex. J Biol Chem 279, 32116-32124.

Tseng, C. P., Yu, C. C., Lin, H. H., Chang, C. Y. \& Kuo, J. T. (2001). Oxygen- and growth rate-dependent regulation of Escherichia coli fumarase (FumA, FumB, and FumC) activity. J Bacteriol 183, 461-467.

van Schie, B. J., Hellingwerf, K. J., van Dijken, J. P., Elferink, M. G., van Dijl, J. M., Kuenen, J. G. \& Konings, W. N. (1985). Energy transduction by electron transfer via a pyrrolo-quinoline quinonedependent glucose dehydrogenase in Escherichia coli, Pseudomonas aeruginosa, and Acinetobacter calcoaceticus (var. Iwoffi). J Bacteriol 163, 493-499.

Wang, G. \& Maier, R. J. (2004). An NADPH quinone reductase of Helicobacter pylori plays an important role in oxidative stress resistance and host colonization. Infect Immun 72, 1391-1396.
Wilcox, S. K., Cavey, G. S. \& Pearson, J. D. (2001). Single ribosomal protein mutations in antibiotic-resistant bacteria analyzed by mass spectrometry. Antimicrob Agents Chemother 45, 3046-3055.

Witte, G., Urbanke, C. \& Curth, U. (2003). DNA polymerase III chi subunit ties single-stranded DNA binding protein to the bacterial replication machinery. Nucleic Acids Res 31, 4434-4440.

Wolf, S. G., Frenkiel, D., Arad, T., Finkel, S. E., Kolter, R. \& Minsky, A. (1999). DNA protection by stress-induced biocrystallization. Nature 400, 83-85.

Wright, N. E. \& Gilbert, P. (1987). Antimicrobial activity of nalkyltrimethylammonium bromides: influence of specific growth rate and nutrient limitation. J Pharm Pharmacol 39, 685-690.

Wu, J. \& Weiss, B. (1992). Two-stage induction of the soxRS (superoxide response) regulon of Escherichia coli. J Bacteriol 174, 3915-3920.

Yamada, M., Asaoka, S., Saier, M. H., Jr \& Yamada, Y. (1993a). Characterization of the gcd gene from Escherichia coli K-12 W3110 and regulation of its expression. J Bacteriol 175, 568-571.

Yamada, M., Sumi, K., Matsushita, K., Adachi, O. \& Yamada, Y. (1993b). Topological analysis of quinoprotein glucose dehydrogenase in Escherichia coli and its ubiquinone-binding site. J Biol Chem 268, 12812-12817.

Zgurskaya, H. I. \& Nikaido, H. (2000). Cross-linked complex between oligomeric periplasmic lipoprotein AcrA and the inner-membraneassociated multidrug efflux pump AcrB from Escherichia coli. J Bacteriol 182, 4264-4267.

Zheng, M., Wang, X., Templeton, L. J., Smulski, D. R., LaRossa, R. A. \& Storz, G. (2001). DNA microarray-mediated transcriptional profiling of the Escherichia coli response to hydrogen peroxide. J Bacteriol 183, 4562-4570.

Edited by: I. R. Henderson 